\title{
An unusual case of Parinaud's syndrome
}

\author{
Maria Mallia, Charmaine Chircop, Josanne Aquilina
}

Department of Medicine, Mater Dei Hospital, Msida, Malta

Correspondence to Maria Mallia, mariamallia@live.co.uk

\section{Summary}

A 25-year-old man presented with blurred vision, headache and dizziness. On questioning, there was also a history of a preceding diarrhoeal illness. Initial investigations were normal. However, after a week, he represented with a Parinaud's syndrome. In view of the preceding diarrhoea, the transient unsteadiness and the areflexia on examination, anti-G01b antibodies were requested. The resulting titre was positive confirming the suspected diagnosis of Miller Fisher syndrome. He responded to intravenous immunoglobulins with full resolution of his symptoms and signs. Although various unusual neuro-ophthalmological signs have been reported localising to the brainstem, to our knowledge, this is the first case report of Parinaud's syndrome being the presenting symptom of Miller Fisher syndrome.

\section{BACKGROUND}

We think that this case is important since, to our knowledge, it is the first description of Miller Fisher syndrome presenting with Parinaud's syndrome in medical literature. This case could help alert other clinicians to the possibility of an underlying, treatable demyelinating condition when patients present with unexplained Parinaud's syndrome.

\section{CASE PRESENTATION}

A 25-year-old man presented with a history of visual disturbance for a few days. Symptoms were rather nonspecific and included blurring of vision which fluctuated during the day. Mild headache and dizziness were also present and attributed to the strain caused by his visual disturbance.

The patient had no history of any significant medical illnesses in the past. He had been prescribed as a tricyclic antidepressant (Nortriptyline) by his general practitioner for anxiety in the previous 3 weeks but was on no other medication. He was a university student reading for a philosophy degree. At the time of presentation, no definite neurological signs were present.

Investigations requested included a chest x-ray (CXR) and serum acetylcholine receptor antibodies for the possibility of ocular myasthenia. These were both within normal limits. An MRI of the brain was performed and was also normal.

However, after a week, the patient complained of worsening visual symptoms and was actually keeping his head tilted backwards with his eyelids half-closed. Further clinical evaluation revealed that he had developed a Parinaud's syndrome with paralysis of upward gaze and convergence nystagmus. Voluntary saccades and pursuit movements were normal. The pupils were equal, and reactive to both light and accommodation. The diagnosis of Parinaud's syndrome was confirmed by a specialist optometrist and ortoptist.

Examination of the rest of his neurological system revealed no other signs except for areflexia.
On further questioning, it emerged that, about 3 weeks before his first presentation, he had suffered a diarrhoeal illness for only 1 day. Just a few days after that, he had been mildly unsteady, a symptom which he attributed to the Nortriptyline which had just been started. This unsteadiness resolved spontaneously.

Because of the confirmed Parinaud's syndrome, another MRI of the brain with gadolinium was performed with particular attention for tectal lesions with enhancement possibly suggestive of active inflammatory demyelination. This was, however, again negative. In view of the preceding diarrhoeal illness, the transient unsteadiness and the areflexia, anti-GQ1b antibodies were requested. The resulting titre was positive, confirming the suspected diagnosis of Miller Fisher syndrome. The patient was reluctant to have a lumbar puncture performed. Serum Campylobacter jejuni antibody levels were borderline.

A decision to treat with intravenous immunoglobulins was taken in view of his distressing visual symptoms. These started to resolve after about a week from starting treatment and he is now completely symptom-free with resolution of all his clinical signs.

\section{INVESTIGATIONS}

- CXR-no abnormalities detected

- Serum acetylcholine receptor antibodies-normal

- MRI of the brain-normal

- Repeat MRI brain with gadolinium-normal

- Anti-GQ1b antibodies-positive titre

- Serum C jejuni antibodies-borderline result

- Cerebrospinal fluidS analysis was refused by the patient.

- Nerve conduction studies-normal

\section{DIFFERENTIAL DIAGNOSIS}

Whipple's disease was not considered in the differential diagnosis because there were no systemic or other neurological features to suggest this extremely rare condition, and indeed, the patient's symptoms resolved completely within a few weeks. 


\section{TREATMENT}

Intravenous immunoglobulins.

\section{OUTCOME AND FOLLOW-UP}

The patient is now completely symptom-free and has been discharged from neurology clinic.

\section{DISCUSSION}

Parinaud's syndrome, also known as the sylvian aqueduct or pretectal syndrome, results from damage to the pretectum, posterior commissure and superior colliculus. ${ }^{1}$ It is named after Henri Parinaud (1844-1905), considered to be the father of French ophthalmology. This syndrome presents with vertical supranuclear palsy, affecting either upgaze alone or both upgaze and downgaze (sparing the vestibule ocular reflex range), impaired pupillary light reactions and a light-near dissociation. Collier's lid retraction sign and skew deviation may be present. A classic sign is convergence-retraction nystagmus, (the eyes pull in and the globes retract on fast upgaze). Fragments of the pretectal syndrome are common. Some consider vertical gaze palsy, convergence-retraction nystagmus, and impaired pupillary light reflexes as the key signs, ${ }^{1}$ but modern imaging shows that pretectal lesions can have even more minimal presentations, such as slow vertical saccades instead of limited vertical range, and lid lag rather than lid retraction. ${ }^{2}$

The most common causes are tumours, strokes (collicular branches of the posterior choroidal artery), and obstructive hydrocephalus below the sylvian aqueduct. ${ }^{1}$

Thalamic haemorrhages are more common than ischaemic strokes, and tumours are located equally in the thalamus and pineal gland. Encephalitis, demyelination, brain abscess, trauma, posterior tentorial herniation and Wernicke's syndrome are rare causes.

Miller Fisher syndrome is an acute demyelinating disorder that is considered a cranial nerve variant of Guillain-Barré syndrome. It was originally described in 1956 as a triad of total external ophthalmoplegia, ataxia and loss of tendon reflexes. ${ }^{3}$ However, it may rarely present with atypical clinical features, such as bulbar involvement or limb weakness or without one of the three components. Miller Fisher syndrome occurs in more men than women by a ratio of approximately $2: 1 .^{4}$ The mean age of onset of Miller Fisher syndrome is 43.6 years, ${ }^{4}$ though the onset has been documented in individuals between the ages of 13 and 78 years. ${ }^{5}$ A preceding infection has been identified in about $70 \%$ of patients with Miller Fisher syndrome, as it is in Guillain-Barré syndrome. Immunoglobulin G (IgG) anti-GOlb antibody, activated by certain strains of $C$ jejuni are found in over $90 \%$ of cases of Miller Fisher syndrome. They have a relatively high specificity and sensitivity for Miller Fisher syndrome. Dense concentrations of GQ1b ganglioside are found in the oculomotor nerve (cranial nerve III), trochlear nerve (cranial nerve IV) and abducens nerve (cranial nerve VI) of patients with Miller Fisher syndrome, which may explain the relationship between anti-GQ1b antibodies and ophthalmoplegia. ${ }^{4} 6$ Titres of anti-GQ1b antibodies in CSF that are greater than 1:40 are specific for Miller Fisher syndrome. ${ }^{4}$

The documented ophthalmological features of the Miller Fisher syndrome include isolated abducens nerve palsy, ${ }^{7}$ lid retraction, isolated ptosis, ${ }^{8} 9$ internuclear ophthalmoplegia, ${ }^{10}$ divergence paralysis, convergence spasm, defective vestíbulo-ocular reflex, chronic ophthalmoplegia, areflexic mydriasis, ${ }^{11}{ }^{12}$ convergence failure, optic neuritis $^{13}$ and Collier's sign. ${ }^{14}$

A single case report was found where a dorsal midbrain syndrome was documented in CANOMAD (chronic ataxic neuropathy with ophthalmoplegia, IgM paraprotein, cold agglutinins and anti GD1b disialosyl antibodies), which is associated with anti GD1b antibodies. ${ }^{15}$

Although various unusual neuro-ophthalmological signs have been reported localising to the brainstem, to our knowledge, this is the first case report of Parinaud's syndrome being the presenting symptom of Miller Fisher syndrome. We propose that after exclusion of structural lesions in the dorsal midbrain, Miller Fisher syndrome should be considered in the differential diagnosis of the causes of Parinaud's syndrome. We further hypothesise that ganglioside GQ1b, or a similar molecule is present in the tectal region of the midbrain, and can be a target of the antibodies in Miller Fisher syndrome.

Learning points

- Miller Fisher syndrome is an acute demyelinating disorder, a variant of Guillain-Barré syndrome.

- Miller Fisher syndrome was described as a triad of total external ophthalmoplegia, ataxia and loss of tendon reflexes.

- Key features of Parinaud's syndrome include, vertical gaze palsy, convergence-retraction nystagmus and impaired pupillary light reflexes.

- Parinaud's syndrome can be the presenting feature of Miller Fisher syndrome.

\section{Competing interests None.}

Patient consent Obtained.

\section{REFERENCES}

1. Keane JR. The pretectal syndrome: 206 patients. Neurology 1990; 40:684-90

2. Galetta SL, Raps EC, Liu GT, et al. Eyelid lag without eyelid retraction in pretectal disease. J Neuroophthalmol 1996:16:96-8.

3. Fisher M. An unusual variant of acute idiopathic polyneuritis (syndrome of ophthalmoplegia, ataxia and areflexia). N Engl J Med 1956;255:57-65

4. Berlit $\mathbf{P}$, Rakicky J. The Miller Fisher syndrome. Review of literature. J Clin Neuroophthalmol. 1992:12:57-63.

5. Mori M, Kuwabara S, Fukutake T, et al.Clinical features and prognosis of Miller Fisher syndrome. Neurology 2001;56:1104-6.

6. Winer JB. Guillain Barre syndrome. Mol Pathol 2001:54:381-5.

7. Wertheim MS, Benzimra JD, Jadresic LP, et al. Ocular presentation of pediatric Miller-Fisher syndrome. J Pediatr Ophthalmol Strabismus 2008:45:245-6.

8. Jindal G, Parmar VR, Gupta VK. Isolated ptosis as acute ophthalmoplegia without ataxia, positive for anti-GQ1b immunoglobulin G. Pediatr Neurol 2009;41:451-2.

9. Stalpers XL, Verhagen W, Meulstee J. Isolated bilateral ptosis as the only ophthalmologic sign in the fisher variant of Guillain-Barre syndrome. J Neuroophthalmol 2009;29:354.

10. Bae JS, Kim JK, Kim SH, et al. Bilateral internal ophthalmoplegia as an initial sole manifestation of Miller Fisher syndrome. J Clin Neurosci 2009;16:963-4. 


\section{BMJ Case Reports}

11. Nitta T, Kase M, Shinmei $Y$, et al. Mydriasis with light-near dissociation in Fisher's syndrome. Jpn J Ophthalmol 51:224-7.

12. Fleury V, Aqallal A, Lagrange $E$, et al. Acute bilateral mydriasis associated with anti-GQ1b antibody. J Clin Neurosci 2010;17:514-15.

13. Lolekha $\mathbf{P}$, Phanthumchinda K. Optic neuritis in a patient with Miller-Fisher syndrome. J Med Assoc Thai 2008;91:1909-13.
14. Miyashi M, Hemmi S, Hagiwara H, et al. Collier's sign in Miller Fisher Syndrome. Rinsho Shinkeigaku 2006;46:712-14.

15. Arbogast SD, Khanna S, Koontz DW, et al. Chronic ataxic neuropathy mimicking dorsal midbrain syndrome. J Neurol Neurosurg Psychiatry 2007;78:1276-7.

Copyright 2012 BMJ Publishing Group. All rights reserved. For permission to reuse any of this content visit

http://group.bmj.com/group/rights-licensing/permissions.

BMJ Case Report Fellows may re-use this article for personal use and teaching without any further permission.

Please cite this article as follows (you will need to access the article online to obtain the date of publication).

Mallia M, Chircop C, Aquilina J. An unusual case of Parinaud's syndrome. BMJ Case Reports 2012;10.1136/bcr-2012-006722, Published XXX

Become a Fellow of BMJ Case Reports today and you can:

- Submit as many cases as you like

- Enjoy fast sympathetic peer review and rapid publication of accepted articles

Access all the published articles

- Re-use any of the published material for personal use and teaching without further permission

For information on Institutional Fellowships contact consortiasales@bmjgroup.com

Visit casereports.bmj.com for more articles like this and to become a Fellow 